\title{
Ultrastructural analysis of sperm from the genus Idarnes (Hymenoptera: Chalcidoidea, Sycophaginae)
}

\author{
Khesller Patrícia OlaZiA ${ }^{1,2}$; Juliana Souza DA Silva ${ }^{1}$; Guilherme Sirimarco de Souza TONElli ${ }^{1}$; Sônia Nair BÁO ${ }^{1, *}$ \\ ${ }^{1}$ Departamento de Biologia Celular, Instituto de Ciências Biológicas, Universidade de Brasília, Brasília, Brazil \\ 2 Instituto de Ciências da Saúde, Coordenação de Ciências Biológicas, Universidade Paulista UNIP, Brasília, Brazil
}

Key words: Chalcidoidea, Idarnes genus, Insect sperm, Sperm ultrastructure, Fig wasps

\begin{abstract}
In this study, the sperm ultrastructure of three species of Idarnes genus was investigated using light and transmission electron microscopy. Spermatozoon morphology of the three species was similar to that of most Chalcidoidea, with helicoidally twisted nucleus and flagellum. The head region consists of an acrosome and a nucleus; the nucleus-flagellum transition region characterized by the presence of mitochondrial derivatives and the centriolar adjunct; a flagellum region, which includes the axoneme with microtubular arrangement $9+9+2$ and two mitochondrial derivatives. However, the sperm of these three species exhibit features that discriminate one species from each other: (1) only one species, Idarnes sp. 2 (carme group) exhibited an extracellular sheath surrounding the anterior portion of the nucleus, which extends to the anterior region of the flagellum, but it did not present filaments; (2) the acrosome in the three species was quite different, Idarnes sp. 1 and Idarnes sp. 2 (carme group) has two compartments (acrosomal and subacrosomal vesicles) while Idarnes sp. 3 (flavicollis group) has a third compartment (perforatorium); (3) the centriolar adjunct elongated and its location among the mitochondrial derivatives is similar for the three species analyzed; (4) mitochondrial derivatives differ between the species, with triangular (Idarnes sp. 1 and sp. 3) and elongated or flat shaped (Idarnes sp. 2) appearance. These data shows that sperm structure may differ within the same genus and confirms the potential of these cells in phylogenetic and taxonomic analyses in the Chalcidoidea superfamily, as well as in Hymenoptera in general.
\end{abstract}

\section{Introduction}

Idarnes is the second most common genus within the subfamily Sycophaginae, with 23 described species for the Americas (Bouček, 1993; Farache et al., 2017). The genus Idarnes is subdivided into three species-groups (incertus, flavicollis and carme) and considered monophyletic (Cruaud et al., 2011a; Cruaud et al., 2011b). The spermatozoon morphology of Idarnes wasps was first described by Pereira et al. (2008) using light microscopy.

The ultrastructural investigation of spermatozoa is widely accepted as a feasible approach by which to better comprehend and resolve the phylogeny and taxonomy of insects. Sperm cells are inherently connected to copulation and fecundation and are constantly under evolutionary pressure. Therefore, spermatozoa are commonly understood as holders of a species-specific set of features (Jamieson, 1987, Dallai et al., 2011; Gottardo et al., 2012).

*Address correspondence to: Sônia Nair Báo, snbao@unb.br Received: 01 April 2021; Accepted: 26 May 2021
There are few published studies concerning spermatozoon ultrastructure of species in the Chalcidoidea superfamily. However, the available characterization studies demonstrate satisfactory ultrastructural diversity capable of constituting a system of features (Quicke et al., 1992; Lino-Neto et al., 1999, Lino-Neto et al., 2000a; Lino-Neto and Dolder, 2001a; Fiorillo et al., 2008; Santos et al., 2013, Santos et al., 2016) that can be investigated in systematic studies and may further aid classification of species. The Chalcidoidea spermatozoon presents spiraled mitochondrial derivatives, nucleus and axoneme (Lino-Neto et al., 2000a; Fiorillo et al., 2008; Brito et al., 2009; Santos et al., 2013, Santos et al., 2016). This, in fact, differs from most described Hymenoptera species.

Considering the object of this study, a better comprehension of which set of characteristics are speciesspecific can possibly assist in more accurate positioning of the subfamily Sycophaginae and may elaborate on descriptions and comparisons of the understudied genus Idarnes, leading to a more coherent comprehension of phylogenetic relationships in fig wasps. In this study, we provide ultrastructural cellular characterization of 
spermatozoa belonging to three different species of the Idarnes genus.

\section{Materials and Methods}

Male specimens of the three species (Idarnes sp. 1, Idarnes sp. 2-both belonging to carme group; and Idarnes sp. 3flavicollis group) were collected at the University of São Paulo (USP) campus located in the city of Ribeirão Preto (São Paulo, Brazil) during the months of April 2008 and January, June, August, and September of 2009. Sample sets were stored at the collection of fig wasps of the Laboratório de Biologia Reprodutiva de FicusDepartamento de Biologia da Faculdade de Filosofia, Ciências e Letras, USP-Ribeirão Preto. The material is cared for by Dr. R.A.S. Pereira.

\section{Light microscopy}

Males were dissected and their testes were smeared on clean glass microscope slides to release the sperm within them and fixed in a solution of $4 \%(\mathrm{wt} / \mathrm{vol})$ paraformaldehyde in $0.1 \mathrm{M}$ sodium phosphate buffer, $\mathrm{pH}$ 7.2. After this, the glass microscope slides with the sperm cells were dried at room temperature. After, these preparations were stained for $15 \mathrm{~min}$ with $0.2 \mu \mathrm{g} / \mathrm{mL}$ 4, 6-diamino-2-phenylindole (DAPI) in PBS, washed and mounted with a solution of anti-fade reagent -ProLong Gold. They were then examined by Axiophot microscopes equipped with epifluorescence (Zeiss, Jena, Alemanha).

\section{Transmission electron microscopy}

The testes were dissected in phosphate buffered saline (PBS) and further fixed for $4 \mathrm{~h}$ in a solution containing $2.5 \%$ glutaraldehyde (Electron Microscopy Sciences, Washington, USA), $4 \%$ paraformaldehyde (Sigma-Aldrich, St Louis, USA), $5 \mathrm{mM} \mathrm{CaCl}_{2}$ and $3 \%$ sucrose, buffered in $0.1 \mathrm{M}$ sodium cacodylate, at $\mathrm{pH}$ 7.2. After fixation, the specimens were rinsed in the same buffer, and post-fixed in $1 \%$ osmium tetroxide (Electron Microscopy Sciences, Washington, USA), $0.8 \%$ potassium ferricyanide, and $5 \mathrm{mM}$ $\mathrm{CaCl}_{2}$ in $0.1 \mathrm{M}$ sodium cacodylate buffer. In some cases, the specimens were fixed in a mixture of $2.5 \%$ glutaraldehyde, $1 \%$ tannic acid in $0.1 \mathrm{M}$ phosphate buffer, at $\mathrm{pH} 7.2$, followed by block-staining in $1 \%$ uranyl acetate in distilled water (Afzelius, 1988). The material was dehydrated in gradual acetone series (30-100\%) and embedded in Spurr's resin (Electron Microscopy Sciences, Washington, USA). Ultrathin sections were stained with uranyl acetate and lead citrate and observed using a Jeol 1011 transmission electron microscope (Jeol, Tokyo, Japan) operating at $80 \mathrm{kV}$.

For detection of basic proteins, the ethanolic phosphotungstic acid method (E-PTA), modified from Bloom and Aghajanian (1968), was applied. Testes were fixed with $2.5 \%$ glutaraldehyde in $0.1 \mathrm{M}$ phosphate buffer, $\mathrm{pH}$ 7.4, for $4 \mathrm{~h}$ at $4^{\circ} \mathrm{C}$. After washing in phosphate buffer and dehydrating in alcohol, the material was treated "in bloc" with a solution of $2 \%$ of PTA in absolute ethanol for $24 \mathrm{~h}$ at $4^{\circ} \mathrm{C}$, washed in absolute ethanol and embedded in Spurr's resin. Some ultrathin sections were observed, unstained or stained with uranyl acetate.

\section{Measurements}

Ten different micrographs were measured for each species and the size of each structure observed is represented by the mean length. Mitochondrial derivatives were measured based on the distance between the center of two adjacent derivatives.

\section{Results}

All three species present elongated cells and are helically twisted along its entire length. Sperm cells are divided into three regions: the anterior region, which corresponds to the head, where the nucleus and the acrosome are found; the nucleus-flagellum transition presenting the centriolar adjunct and mitochondrial derivatives; and the posterior, corresponding to the flagellum, which in turn is composed of the axoneme, with a $9+9+2$ microtubular arrangement, and a pair of mitochondrial derivatives (Fig. 1).

\section{Head region}

The acrosome is located at the apex of the nucleus and has a different shape for the three species, as seen in longitudinal (Figs. 2A-2C) and transversal sections (Figs. 2D-2F). In Idarnes sp. 1 (carme group) the acrosome is long and divided into two compartments (Fig. 2A), the subacrosomal vesicle-approximately $180 \mathrm{~nm}$ in length; and the acrosomal vesicle, $715 \mathrm{~nm}$ long. The acrosomal vesicle has an oval shape, and at its upper end a paracrystalline structure (Fig. 2A) is found, best seen in cross-section (Fig. 2D). Wasps Idarnes sp. 2 (carme group) present an acrosome covered by the extracellular layer, which is small, oval, and bicompartmentalized (Figs. 2B and 2E). The subacrosomal vesicle is approximately $100 \mathrm{~nm}$, and the acrosomal vesicle is $195 \mathrm{~nm}$ in length. In Idarnes sp. 3 (flavicollis group) this structure is quite elongated, composed of three compartments (Fig. 2C), the perforatorium, approximately $560 \mathrm{~nm}$, the subacrosomal vesicle, $705 \mathrm{~nm}$ in length, and the acrosomal vesicle, $870 \mathrm{~nm}$ in length. These compartments can also be seen in cross-section (Fig. 2F).

Nuclear chromatin is highly compacted, homogeneous, and electron-dense (Figs. 2G-2J). The torsion of the nucleus can be noted either in longitudinal sections (Figs. 2G and $2 \mathrm{H}$ ) or in cross-sections (Figs. 2I and 2J) clearly indicated by the irregular shape of the structure observed. The nucleus also presents positive electron density for E-PTA prepared samples (not shown) evidencing the presence of basic proteins. Idarnes sp. 2 (carme group) was the only species presenting an extracellular layer covering the nucleus (Figs. 2H and 2J).

\section{Nucleus-flagellum transition region}

The region of the nucleus-flagellum transition is characterized by the presence of mitochondrial derivatives and the centriolar adjunct. In these species, the mitochondrial derivatives insert at the initial portion of the flagellum in the base of the nucleus. All three species studied by us present an elongated centriolar adjunct, as seen in longitudinal sections (Figs. 3A-3C). This structure is surrounded by the mitochondrial derivatives, as also observed in cross-sections (Figs. 3D and 3E). The centriolar adjunct is observed surrounding the centriole and is not inserted right at the 


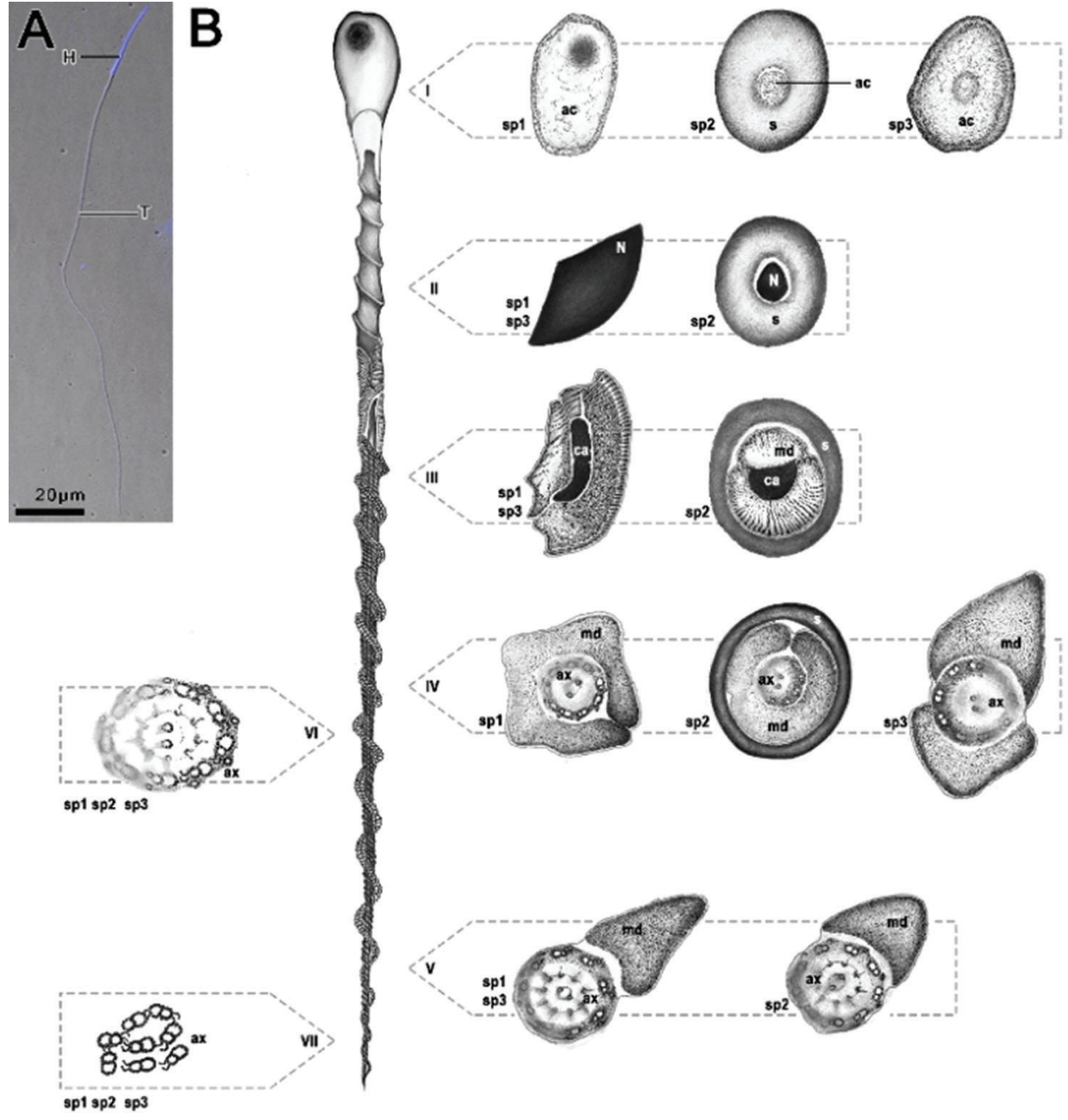

FIGURE 1. Fluorescent micrograph of Idarnes sp. 1 stained with DAPI (A) and schematic representation of spermatozoa of the three species analyzed (B) belonging to the Idarnes genus-sp. 1 and sp. 2 (carme group) and sp. 3 (flavicollis group), corresponding to the longitudinal and cross sections. (i) acrosome region; (ii) nuclei region; (iii) beginning of mitochondrial derivative, centriolar adjunct region; (iv) flagellar region; (v) ending of the flagellar region; (vi, vii) ending piece of flagellum. Abbreviations: Acrosome (ac), axoneme (ax), centriolar adjunct (ca), head region $(\mathrm{H})$, mitochondrial derivative (md), nucleus ( $\mathrm{n}$ ), and extracellular layer (s), tail region $(\mathrm{T})$. base of the nucleus but is rather found immediately under it (Figs. $3 \mathrm{~A}$ and $3 \mathrm{~B}$ ). In the species of the genus Idarnes, the centriolar adjunct is observed along the centriolar region (Figs. $3 \mathrm{C}$ and $3 \mathrm{H}$ ). This structure is characterized by its electrondense aspect, when prepared with tannic acid (Figs. 3A and 3D). However, in E-PTA preparations, it is possible to observe this structure with electron lucid aspect (Fig. 3C).

The extracellular layer is observed in longitudinal sections (Fig. 3B) and in cross-sections (Fig. 3D), covering this region of the spermatozoon in Idarnes sp. 2 (carme group).

\section{Flagellar region}

In the three Idarnes species, the axoneme torsion is easily observed in longitudinal sections (Figs. $4 \mathrm{~A}$ and $4 \mathrm{~B}$ ) and is evident also in transverse sections (Figs. 4C-4J). Another structure where the flagellum torsion can be noted is the pair of mitochondrial derivatives, which sometimes appear near or far away from each other (Figs. 4D and 4F). The orientation of dynein arms reveals that the axoneme is shown as seen from the tail towards the nucleus (anticlockwise oriented, Figs. 4C-4G) and from the centriole towards the tail end (clockwise oriented, Figs. 4H-4J).

In sperm from Idarnes sp. 1 (carme group), the torsion observed in the pair of mitochondrial derivatives located in the intermediate portion of the flagellum is approximately $1.3 \mu \mathrm{m}$, while in the species of Idarnes sp. 2 (carme group) and Idarnes sp. 3 (flavicollis group) is $0.6 \mu \mathrm{m}$ and $1.6 \mu \mathrm{m}$, respectively. Thus, it appears that the torsion is less accentuated in Idarnes sp. 2 (carme group).

Mitochondrial derivatives differ in the three species, both in shape and size (Figs. 3F-3H, 4C, 4D, and 4F). In longitudinal sections, the mitochondrial derivatives of wasps Idarnes sp. 1 (carme group) (Fig. 4A) and Idarnes sp. 3 (flavicollis group) (not shown) are pointed, whereas in wasps of Idarnes sp. 2 (carme group) (Fig. 4B) they are flat and long. In cross-sections, the derivatives of Idarnes sp. 1 (carme group) (Figs. 3E, 3F, 4C, and 4D) and Idarnes sp. 3 (flavicollis group) (Figs. $3 \mathrm{H}$ and 4E) present subtle differences in their size, with a triangular shape. In Idarnes sp. 2 (carme group) the derivatives have similar sizes, are flat and long in the proximal region of the flagellum (Figs. $3 \mathrm{G}$ and $4 \mathrm{~F}$ ) and oval in the distal region (Fig. 4G). In the final portion of the flagellum, they end at different locations (Figs. $4 \mathrm{E}$ and $4 \mathrm{G}$ ). In wasps of Idarnes sp. 2 (carme group), the mitochondrial derivatives are surrounded by the extracellular layer only in the anterior region of the flagellum, as is observed in longitudinal section (Fig. 4B), and in cross-section (Fig. 3G).

The axoneme has a $9+9+2$ microtubular arrangement (Fig. $4 \mathrm{H}$ ), with two central microtubules, nine peripheral pairs and nine accessory microtubules located more externally. Between the accessory microtubules, an intertubular material with electron-dense aspect was observed (Figs. $4 \mathrm{H}$ and 4I). However, this arrangement $(9+9+2)$ is 

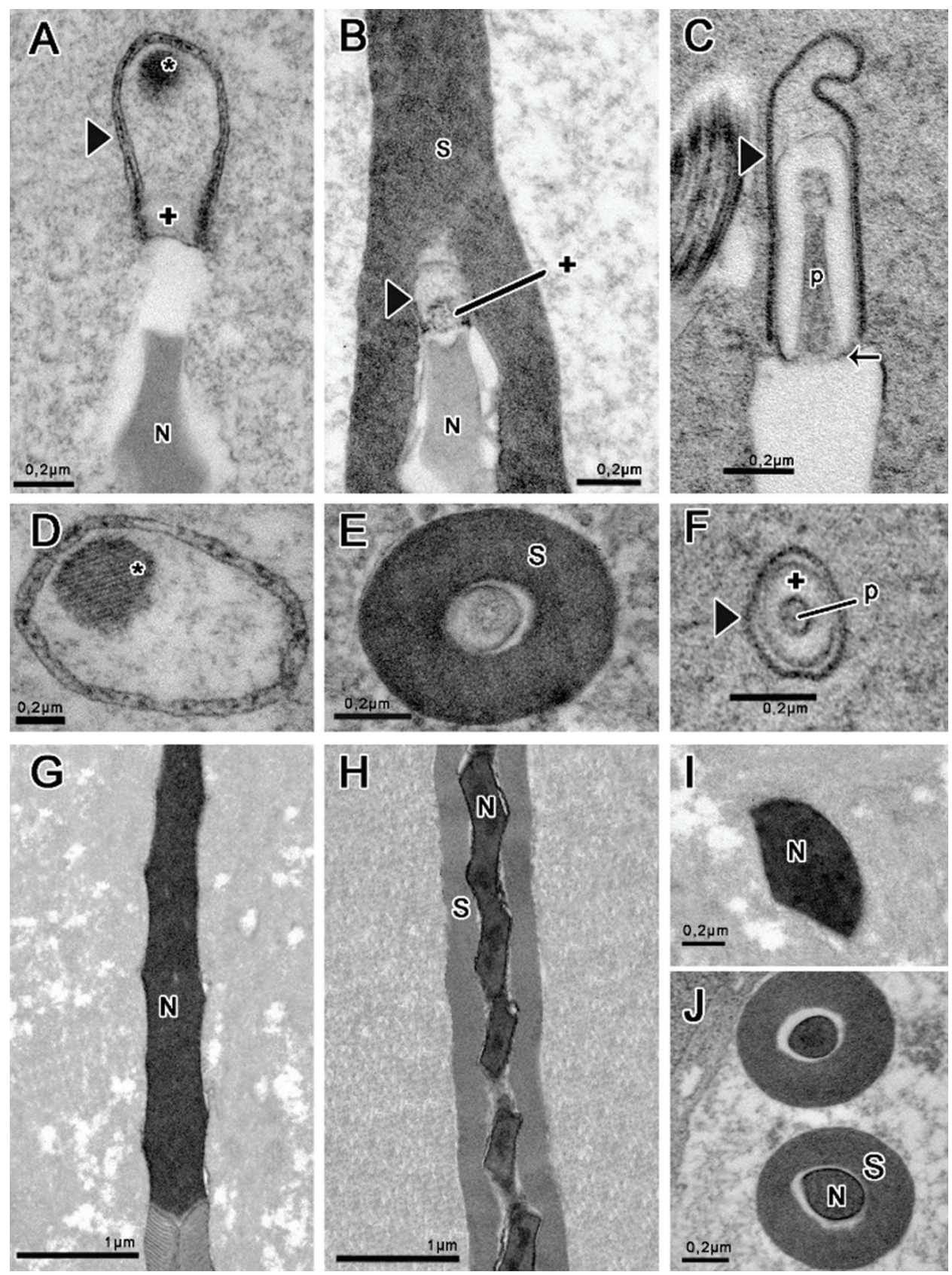

FIGURE 2. Head region prepared with tannic acid (A-B, D-F, J) and routine for transmission electron microscopy (C, G-I). (A, D, G, I) Idarnes sp. 1 (carme group); (B, E, H, J) Idarnes sp. 2 (carme group); (C, F) Idarnes sp. 3 (flavicollis group). Acrosome in longitudinal section

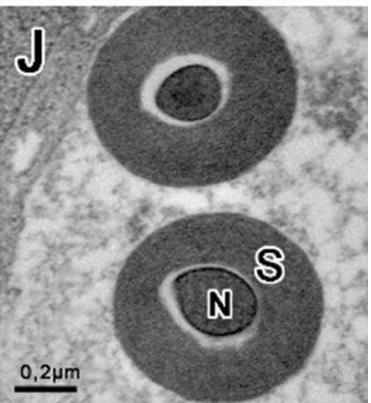
(A-C), and cross-sections evidencing the shapes (D-F). Nucleus in longitudinal section (G-H) and crosssection (I-J). Abbreviations: Acrosomal vesicle (arrowhead); Extracellular layer (S); Nucleus (N); Paracrystalline material (asterisk); Perforatorium (p); Subacrosomal vesicles $(+)$ and the insertion of perforatorium into the nucleus (arrow).

sequentially disassembled in the final portion of the axoneme (Figs. 4I-4K). At the end of the flagellum, the accessories are the first to disassemble (Fig. 4I); then the central ones (Fig. 4J) and, finally, the peripheral pairs, which, before the terminal end, are seen to be disorganized (Fig. 4K).

\section{Discussion}

Idarnes spermatozoa present different sizes, as described by Pereira et al. (2008) and have a basic structure similar to other Chalcidoidea already described in literature, such as Bephratelloides pomorum (Eurytomidae) (Lino-Neto et al., 1999); Trichogramma pretiosum and T. atopovirilia (Trichogrammatidae) (Lino-Neto et al., 2000a); Trichogramma dendrolimi (Trichogrammatidae) (Lino-Neto and Dolder, 2001a); Pegoscapus sp. 1, Pegoscapus sp. 2 and P. tonduzi (Agaonidae) (Fiorillo et al., 2008) and Melittobia hawaiiensis and M. australica (Eulophidae) (Brito et al., 2009). In these species, the spermatozoa are long, thin and show a helical structure both in the head region and in the flagellar region; that is, they present a twisted nucleus and flagellum with mitochondrial derivatives running helically through the axoneme. This twisted characteristic of Chalcidoidea differentiates them from many hymenopterans, whose sperm are linear (Quicke et al., 1992; Lino-Neto and Dolder, 2002; Zama et al., 2001, Zama et al., 2004, Zama et al., 2005a; Araújo et al., 2005; Fiorillo et al., 2005; Mancini et al., 2006).

The three studied species of Idarnes present the acrosome anterior to the nucleus. However, the classic structure of the acrosomal complex was only observed in Idarnes sp. 3 (flavicollis group). The acrosomal complex usually consists of the acrosomal vesicle and perforatorium and is present in many hymenopterans (Lino-Neto and Dolder, 2001b (only in Trisolcus basalis), Lino-Neto and Dolder, 2002; Zama et al., 2001, Zama et al., 2004, Zama et al., 2005a, Zama et al., 2005b; Báo et al., 2004; Araújo et al., 2005, Araújo et al., 2009; 

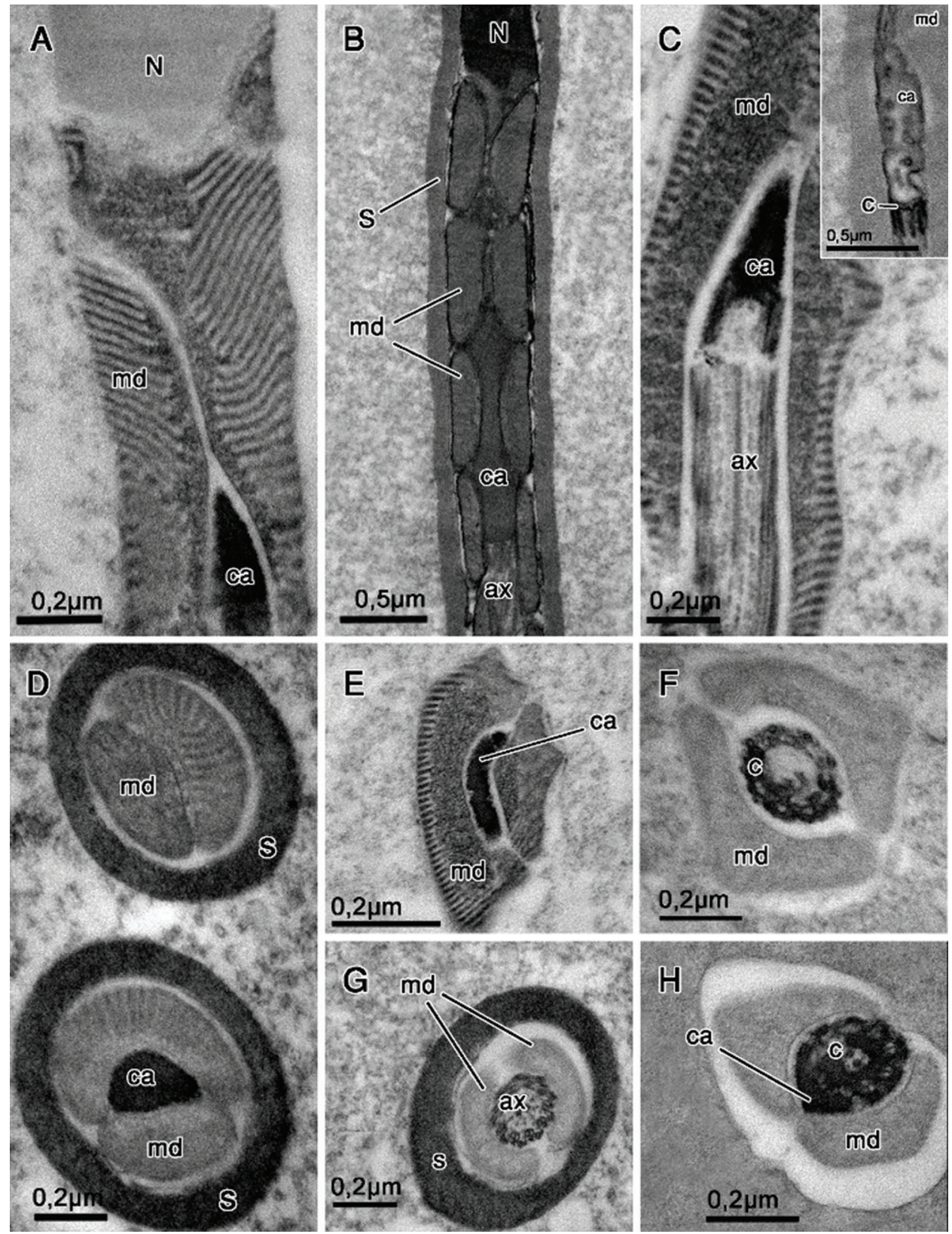

FIGURE 3. Nucleus-flagellum transition region. Tannic acid (A, C-E, G-H), routine for transmission electron microscopy (B) and E-PTA staining ( $\mathrm{F}$ and insert in $\mathrm{C})$. ( $\mathrm{A}, \mathrm{C}$, $\mathrm{E}-\mathrm{F})$ Idarnes sp. 1 (carme group); (B, $\mathrm{D}, \mathrm{G})$ Idarnes sp. 2 (carme group); $(\mathrm{H})$ Idarnes sp. 3 (flavicollis group). Longitudinal sections showing the centriolar adjunct flanked by mitochondrial derivatives $(\mathrm{A}-\mathrm{C})$. Cross-sections of the anterior portion of the flagellum (D-E). Abbreviations: Axoneme (ax), Centriole (C), Centriolar adjunct (ca), extracellular layer (S), Mitochondrial derivative (md), Nucleus (N).

Fiorillo et al., 2005; Lino-Neto et al., 2008; Gracielle et al., 2009; Mancini et al., 2009). Idarnes sp. 2 (carme group) acrosome measures only $195 \mathrm{~nm}$ and is the smallest ever recorded for Chalcidoidea. Reports range from $260 \mathrm{~nm}$ in Eulophidae (Brito et al., 2009) to $1.5 \mu \mathrm{m}$ in Trichogrammatidae (Lino-Neto and Dolder, 2001a).

The conical shape of the acrosomal vesicle and perforatorium, as well as its insertion at the apex of the nucleus in Idarnes sp. 3 (flavicollis group) are similar to that described for Bephratelloides pomorum (Eurytomidae: Chalcidoidea) (Lino-Neto et al., 1999) and other hymenopterans [(Formicidae-Lino-Neto and Dolder, 2002); (Apidae-Báo et al., 2004); (Halictidae-Fiorillo et al., 2005); (Sphecidae-Zama et al., 2005b); (CrabronidaeAraújo et al., 2009); (Vespidae-Mancini et al., 2009)]. In Idarnes sp. 1 and Idarnes sp. 2 (carme group), as well as in other Chalcidoidea (Lino-Neto et al., 2000a; Lino-Neto and Dolder, 2001a; Brito et al., 2009), the perforatorium of the acrosomal complex was not observed. The total absence of the acrosome in chalcidoid species was registered only in three species of Agaonidae (Fiorillo et al., 2008).

In the present study, only Idarnes sp. 2 (carme group) has an extracellular layer. All species differ from other Chalcidoides species already described, with regard to its length and the filaments that radiate from it. In Chalcidoidea, this layer is limited to the acrosome region and the anterior portion of the nucleus (Hogge and King, 1975; Lino-Neto et al., 1999, 2000a; Fiorillo et al., 2008; Brito et al., 2009), in addition to having numerous filaments (Lino-Neto et al., 1999, Lino-Neto et al., 2000a; Fiorillo et al., 2008; Brito et al., 2009). The presence of this structure is believed to be a characteristic of parasitic wasps, since it has been reported not only in chalcidoid wasps, but also in Ichneumonidae (Quicke et al., 1992) and Cynipoidea (Newman and Quicke, 1999a). However, it was not observed in two of the three species of Idarnes analyzed here, and also in Scelionidae (Lino-Neto and Dolder, 2001b). 


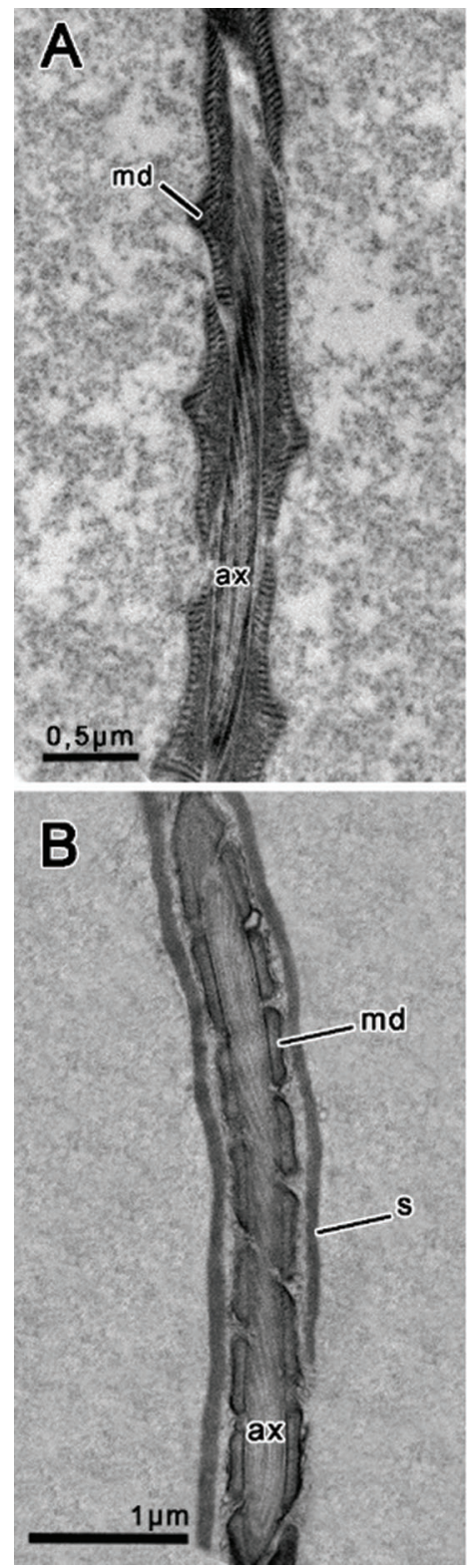

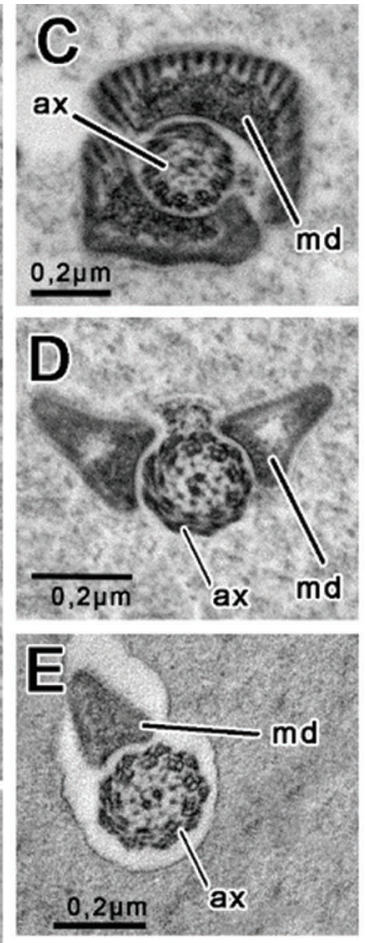

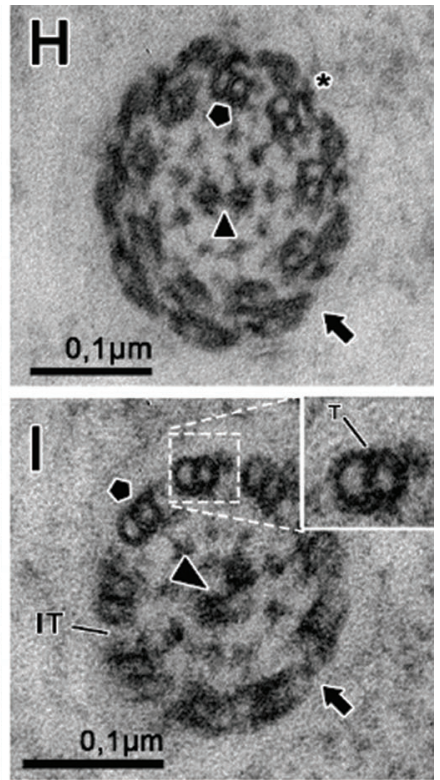

FIGURE 4. Flagellum region prepared with tannic acid (A, C-L) and routine for transmission electron microscopy (B). (A, C, D, H-K) Idarnes sp. 1 (carme group); (B, F-G,) Idarnes sp. 2 (carme group); (E) Idarnes sp. 3 (flavicollis group). Longitudinal (A-B) and cross-sections (C-H) of the flagellum. (C-G) Demonstrates the shape and sequence of disposal of the mitochondrial derivative. $(\mathrm{H}-\mathrm{K})$ Demonstrates the terminal end of the flagellum as seen in cross-sections. In the insert of the Fig. 4I, tubulin ( $t$ ) can be seen on microtubules. Abbreviations: Accessory microtubules (asterisk); Axoneme (ax); Extracellular layer (S); Mitochondrial derivatives (md); Intertubular material (IT); Peripherical microtubule pairs (polygon), pair of central microtubules (arrowhead) and microtubule torsion (arrow).
The helically twisted nucleus, with compacted and homogeneous chromatin, is a characteristic of Chalcidoidea wasps (Lino-Neto et al., 1999, Lino-Neto et al., 2000a; LinoNeto and Dolder, 2001a; Fiorillo et al., 2008; Brito et al., 2009).

The nucleus-flagellum transition region is composed of the nuclear base, centriolar adjunct and the mitochondrial derivatives. It is here that the flagellum is inserted at the base of the nucleus. This insertion is facilitated by the presence of the centriolar adjunct, a characteristic structure of this region, basically made up of ribonucleoproteins and proteins (Taffarel and Esponda, 1980). In Idarnes genus, was detected the presence of the triplet microtubules forming the centriole. This structure is interpreted as being a supporting organelle, and in some other species could be composed of doublet or triplet microtubules, located beneath the nucleus. This structure was also described for species of other groups of insects such as Odonata, Thysanoptera, Lepidoptera, with several variations in morphology (Dallai et al., 2016).

Thus, the E-PTA technique is commonly used in studies of invertebrate spermiogenesis (Báo, 1996; Lino-Neto et al., 1999,
Lino-Neto et al., 2000a; Conte et al., 2005; Zama et al., 2005b, Zama et al., 2007) and vertebrates (Ferreira and Dolder, 2003a, Ferreira and Dolder, 2003b) for the detection of basic proteins. In Idarnes species it was possible to observe that the centriole adjunct is positive for E-PTA, but has electron-lucid spaces, probably due to being composed of different proteins.

In the species of Idarnes studied, the centriolar adjunct is elongated and located between the mitochondrial derivatives. It differs greatly from other Chalcidoidea. In the latter, the centriolar adjunct is short and has a discoid format between the nucleus and the flagellum (Lino-Neto et al., 2000a; LinoNeto and Dolder, 2001a; Fiorillo et al., 2008) with projections extending both in the anterior regions and posterior regions (Lino-Neto et al., 1999, 2000a; Lino-Neto and Dolder, 2001a; Fiorillo et al., 2008; Brito et al., 2009). These projections can be anterior and juxtaposed basolaterally to the nucleus (Lino-Neto et al., 2000a; Brito et al., 2009); only posterior, associated with the onset of the flagellum (Fiorillo et al., 2008); with both anterior and posterior projections (Lino-Neto and Dolder, 2001a); or 
even extending from the centriole in an anterior direction, in a spiral shape around the nucleus (Lino-Neto et al., 1999); in these wasps, the shape of this structure is considered symmetrical. Although other hymenopterans also have an elongated centriolar adjunct, it is located laterally, surrounding the posterior end of the nucleus and the base of mitochondrial derivatives and the axoneme, in an asymmetric arrangement (Newman and Quicke, 1998, Newman and Quicke, 1999a, Newman and Quicke, 1999b; Lino-Neto et al., 2000b; Zama et al., 2001, 2004, Zama et al., 2001, Zama et al., 2005a, Zama et al., 2005b; Báo et al., 2004; Fiorillo et al., 2005; Mancini et al., 2006). In addition to the differences in shape and location, the centriolar adjunct of Idarnes does not appear to reach the base of the nucleus. In these wasps, the centriole adjunct tapers previously, and its connection to the nuclear base is not clearly observed.

The flagellum in Idarnes is organized in the same arrangement as observed in other Chalcidoidea. The axoneme is twisted, with axonemal microtubules in a $9+9$ +2 organization, and a pair of mitochondrial derivatives helically traversing the axoneme (Lino-Neto et al., 1999, Lino-Neto et al., 2000a; Lino-Neto and Dolder, 2001a; Fiorillo et al., 2008; Brito et al., 2009). In the three species, it is located farther from the nucleus, due to the long centriolar adjunct, while in the species of Eurytomidae (Lino-Neto et al., 1999), Trichogrammatidae (Lino-Neto et al., 2000a; Lino-Neto and Dolder, 2001a), Agaonidae (Fiorillo et al., 2008) and Eulophidae (Brito et al., 2009), the axoneme anterior end is located just below the nucleus, after a short centriolar adjunct. On genus Idarnes inner and outer dynein arms were also observed. Usually, this structure can be observed connecting doublet microtubules and has an important role on sperm motility. Intertubular material was also found between the accessory microtubules. Such material is common to other insects (Dallai et al., 2016).

Important differences can be observed by the comparison of mitochondrial derivatives both between the three species of Idarnes and other Chalcidoidea (Wilkes and Lee, 1965; Quicke et al., 1992; Lino-Neto et al., 1999, LinoNeto et al., 2000a; Lino-Neto and Dolder, 2001a; Fiorillo et al., 2008; Brito et al., 2009). These differences basically reside in their format. The triangular, elongated, and flat shapes reported in Idarnes have never been observed in this superfamily. A triangular shape was noted in Idarnes sp. 1 (carme group) and Idarnes sp. 3 (flavicollis group), flattened and elongated in Idarnes sp. 2 (carme group). In other Chalcidoidea, mitochondrial derivatives are generally oval and have similar diameters (Quicke et al., 1992; Lino-Neto et al., 1999, Lino-Neto et al., 2000a; Fiorillo et al., 2008). We observed that the mitochondrial derivative with a larger area presents a constriction that divides it into two portions, the smaller one being closer to the axoneme. In other Hymenoptera, it is common for mitochondrial derivatives to present different sizes (Höfling et al., 1970; Newman and Quicke, 1999a; Zama et al., 2001, Zama et al., 2004, Zama et al., 2005a, Zama et al., 2005b; Báo et al., 2004; Araújo et al., 2005; Fiorillo et al., 2005; Mancini et al., 2006, Mancini et al., 2009; Gracielle et al., 2009).

At the end of the flagellum, these structures can either end with the axoneme, or before it, at different levels. In cases where they present different diameters, smaller area derivatives may end first (Zama et al., 2001, Zama et al., 2004, Zama et al., 2005a), or lastly, in this case, after larger area derivatives end (Brito et al., 2009).

As the axonemal microtubules approach the posterior end of the flagellum, they are disassembled in different sequences, varying between groups of insects. In Idarnes, as in other Chalcidoidea with the exception of Pegoscapus (Fiorillo et al., 2008), the accessory microtubules end first (Lino-Neto et al., 1999; Lino-Neto et al., 2000a; Lino-Neto and Dolder, 2001a; Brito et al., 2009). As observed in some Parasites, the peripheral pairs are the last to end (Newman and Quicke, 1998; Lino-Neto et al., 1999, Lino-Neto et al., 2000a).

Sperm ultrastructure characterization and the differences mentioned on this study provide data that can be used to elucidate issues about the taxonomy and phylogeny of the Sycophaginae subfamily, which is still considered incerta sedis. A more detailed phylogenetic study could place it in a family, or even propose a new family. However, it is necessary to conduct sperm cell characterization of other groups of fig wasps and expand the number of groups studied within the order to compare them and, thus, assist in the establishment of phylogenetic relationships.

Availability of Data and Materials: All data generated or analyzed during this study are included in this published article.

Authors' Contribution: The authors confirm contribution to the paper as follows: study conception and design: K. P. OLAZIA, J. S. da Silva, S. N. Báo; data collection: J. S. da Silva; analysis and interpretation of results: K. P. OLAZIA, G. S. S Tonelli, S. N. Báo; draft manuscript preparation: K. P. OLAZIA, G. S. S. Tonelli. All authors reviewed the results and approved the final version of the manuscript.

Funding Statement: Conselho Nacional de Desenvolvimento Científico e Tecnológico/CNPq (Grant No. 302355/2016-2), Financiadora de Estudos e Projetos/FINEP (Grant No. 01.08.0457.00), Fundação de Amparo à Pesquisa do Distrito Federal/FAPD-DF (Grant No. 00193.00000920/2020-23), and Coordenação de Aperfeiçoamento de Pessoal de Nível Superior/CAPES (Code 001).

Conflicts of Interest: The authors declare that they have no conflicts of interest to report regarding the present study.

\section{References}

Afzelius BA (1988). Microtubules in the spermatids of stick insects. Journal of Ultrastructure and Molecular Structure Research 98: 94-102.

Araújo VA, Moreira J, Lino-Neto J (2009). Structure and ultrastructure of the spermatozoa of Trypoxylon (Trypargilum) albitarse Fabricius 1804 (Hymenoptera: Apoidea: Crabronidae). Micron 40: 719-723.

Araújo VA, Zama U, Dolder H, Lino-Neto J (2005). Morphology and ultrastructure of the spermatozoa of Scaptotrigona xanthotricha Moure (Hymenoptera, Apidae, Meliponini). Brazilian Journal of Morphological Sciences 22: 137-141.

Báo SN (1996). Spermiogenesis in Coelomera lanio (Chrysomelidae: Gallerucinae): Ultrastructural and cytochemical studies. In: 
Jolivet PHA, Cox ML (eds.), pp. 119-132. Chrysomelidae Biology, General Studies.

Báo SN, Simões DG, Lino-Neto J (2004). Sperm ultrastructure of the bees Exomalopsis (Exomalopsis) auropilosa Spinola 1853 and Paratetrapedia (Lophopedia) sp. Michener \& Moure 1957 (Hymenoptera: Apidae: Apinae). Journal Submicroscopic Cytology and Pathology 36: 23-28.

Bloom FE, Aghajanian GK (1968). Fine structure and cytochemical analysis of the staining of synaptic junctions with phosphotungstic acid. Journal of Ultrastructure Research 22: 361-375.

Bouček Z (1993). The genera of chalcidoid wasps from Ficus fruit in the new world. Journal of Natural History 27: 173-217.

Brito P, Lino-Neto J, Dolder H (2009). Sperm structure and ultrastructure of the Melittobia hawaiiensis, Perkins and $M$. australica, Girault (Chalcidoidea: Eulophidae). Tissue and Cell 41: 113-117.

Conte M, Lino-Neto J, Dolder H (2005). Spermatogenesis of Melipona quadrifasciata anthidioides (Hymenoptera: Apidae): Fate of the atypical spermatids. Caryologia 58: 183-188.

Cruaud A, Jabbour-Zahab R, Genson G, Couloux A, Peng YQ et al. (2011a). Out of Australia and back again: The world-wide historical biogeography of non-pollinating fig wasps (Hymenoptera: Sycophaginae). Journal of Biogeography 38: 209-225.

Cruaud A, Jabbour-Zahab R, Genson G, Kjellberg F, Kobmoo N et al. (2011b). Phylogeny and evolution of life history strategies in the Sycophaginae non-pollinating fig wasps (Hymenoptera, Chalcidoidea). BMC Evolutionary Biology 11: 178.

Dallai R, Gottard M, Beutel GR (2016). Structure and evolution of insect sperm: New interpretations in the age of phylogenomics. Annual Reviews of Entomology 61: 123.

Dallai R, Mercati D, Carapelli A, Nardi F, Machida R, Sekiya K, Frati F (2011). Sperm accessory microtubules suggest the placement of Diplura as the sister-group of Insecta s.s. Arthropod Structure \& Development 40: 77-92.

Farache FHA, Cruaud A, Genson G, Rasplus JY, Pereira RAS (2017). Taxonomic revision and molecular phylogenetics of the Idarnes incertus species-group (Hymenoptera, Agaonidae, Sycophaginae). PeerJ 5: e2842.

Ferreira A, Dolder H (2003a). Cytochemical study of spermiogenesis and mature spermatozoa in the lizard Tropidurus itambere (Reptilia: Squamata). Acta Histochemica 105: 339-352.

Ferreira A, Dolder H (2003b). Sperm ultrastructure and spermatogenesis in the lizard, Tropidurus itambere. BIOCELL 27: 353-362.

Fiorillo B, Coelho AAM, Lino-Neto J, Báo SN (2005). Structure and ultrastructure of the spermatozoa of Halictidae (Hymenoptera, Apoidea). Journal Submicroscopic Cytology and Pathology 37: 75-81.

Fiorillo BS, Lino-Neto J, Báo SN (2008). Structural and ultrastructural characterization of male reproductive tracts and spermatozoa in fig wasps of the genus Pegoscapus (Hymenoptera, Chalcidoidea). Micron 39: 1271-1280.

Gottardo M, Mercati D, Dallai R (2012). The spermatogenesis and sperm structure of Timema poppensis (Insecta: Phasmatodea). Zoomorphologie 131: 209-223.

Gracielle IMS, Fiorillo BS, Lino-Neto J, Báo SN (2009). Morphology of the male reproductive system and spermiogenesis in Hypanthidium foveolatum (Alfken, 1930) (Hymenoptera: Apidae: Megachilinae). Micron 40: 419-425.

Höfling MAC, Cruz Landim C, Kitajima E (1970). The fine structure of spermatozoa from the honeybee. Anais da Academia Brasileira de Ciências 42: 69-78.
Hogge MAF, King PE (1975). The ultrastructure of spermatogenesis in Nasonia vitripennis (Walker) (Hymenoptera: Pteromalidae). Journal of Submicroscopic Cytology 7: 81-96.

Jamieson BGM (1987). The ultrastructure and phylogeny of insect spermatozoa. Cambridge: Cambridge University Press.

Lino-Neto J, Báo SN, Dolder H (1999). Structure and ultrastructure of spermatozoa of Bephratelloides pomorum (Fabricius) (Hymenoptera: Eurytomidae). International Journal of Insect Morphology and Embryology 28: 253-259.

Lino-Neto J, Báo SN, Dolder H (2000a). Structure and ultrastructure of spermatozoa of Trichogramma pretiosum Riley and Trichogramma atopovirilia Oatma and Platner (Hymenoptera: Trichogrammatidae). Acta Zoologica 81: 205-211.

Lino-Neto J, Báo SN, Dolder H (2000b). Sperm ultrastructure of the honey bee (Apis mellifera) (L) (Hymenoptera: Apidae) with emphasis on the nucleus-flagellum transition region. Tissue \& Cell 32: 322-327.

Lino-Neto J, Dolder H (2001a). Redescription of sperm structure and ultrastructure of Trichogramma dendrolimi (Hymenoptera: Chalcidoidea: Trichogrammatidae). Acta Zoologica 82: 159-164.

Lino-Neto J, Dolder H (2001b). Ultrastructural characteristics of the spermatozoa of Scelionidae (Hymenoptera: Platygastroidea) with phylogenetic considerations. Zoologica Scripta 30: 89-96.

Lino-Neto J, Dolder H (2002). Sperm structure and ultrastructure of the fire ant Solenopsis invicta (Buren) (Hymenoptera, Formicidae). Tissue \& Cell 34: 124-128.

Lino-Neto J, Dolder H, Mancini K, Mercati D, Dallai R (2008). The short spermatodesm of Arge pagana (Hymenoptera: Symphyta). Tissue \& Cell 40: 185-193.

Mancini K, Lino-Neto J, Campos LAO, Dolder H (2006). Sperm ultrastructure of the wasp Agelaia vicina (Hymenoptera: Vespidae: Polistinae). Insects Sociaux 53: 333-338.

Mancini K, Lino-Neto J, Dolder H, Dallai R (2009). Sperm ultrastructure of the European hornet Vespa crabro (Linnaeus, 1758) (Hymenoptera: Vespidae). Arthropod Structure \& Development 38: 54-59.

Newman TM, Quicke DLJ (1998). Sperm development in the imaginal testes of Aleiodes coxalis (Hymenoptera: Braconidae: Rogadinae). Journal of Hymenoptera Research 7: 25-37.

Newman TM, Quicke DLJ (1999a). Ultrastructure of spermatozoa in Leptopilina (Hymenoptera: Cynipoidea: Eucoilidae). Journal of Hymenoptera Research 8: 197-203.

Newman TM, Quicke DLJ (1999b). Ultrastructure of imaginal spermatozoa of sawflies (Hymenoptera: Symphyta). Journal of Hymenoptera Research 8: 35-47.

Pereira RAS, Lino-Neto J, Prado AP (2008). Sperm morphology: A novel way to associate female-males of highly sexual dimorphic fig wasp species. Symbiosis 45: 143-147.

Quicke DLJ, Ingram SN, Baillie HS, Gaitens PV (1992). Sperm structure and ultrastructure in the Hymenoptera (Insecta). Zoologica Scripta 21: 381-402.

Santos HP, Zama U, Dolder H, Lino-Neto J (2013). Sperm morphology of Trichospilus diatraeae and Palmistichus elaeisis (Hymenoptera: Chalcidoidea: Eulophidae). Micron 51: 36-40.

Santos HP, Barcellos MS, Reis AB, Dolder H, Lino-Neto J (2016). Sperm morphology of Muscidifurax uniraptor (Hymenoptera: Chalcidoidea: Pteromalidae). Arthropod Structure \& Development 45: 307-310.

Taffarel M, Esponda P (1980). Fine structural cytochemistry of the centriolar adjunct in Grasshopper spermatids. Mikroskope 36: $35-42$. 
Wilkes A, Lee PE (1965). The ultrastructure of dimorphic spermatozoa in Hymenoptera Dahlbominus fuscipennis (Zett.) (Eulophidae). Canadian Journal of Genetics and Cytology 7: 609-619.

Zama U, Lino-Neto J, Dolder H (2001). Ultrastructure of spermatozoa in Plebeia (Plebeia) droryana Friese (Hymenoptera: Apidae: Meliponina). Journal of Hymenoptera Research 10: 261-270.

Zama U, Lino-Neto J, Dolder H (2004). Structure and ultrastructure of spermatozoa in Meliponini (stingless bees) (Hymenoptera: Apidae). Tissue \& Cell 36: 29-41.

Zama U, Lino-Neto J, Melo SM, Campos LAO, Dolder H (2005a). Ultrastructural characterization of spermatozoa in euglossine bees (Hymenoptera, Apidae, Apinae). Insects Sociaux 52: 122-131.

Zama U, Brito P, Lino-Neto J, Campos LAO, Dolder H, Báo SN (2005b). Sperm morphology of mud dauber Sceliphron fistularium Dahlbom (Hymenoptera: Apoidea: Sphecidae), as an indication of bees relation. Journal Submicroscopic Cytology and Pathology 37: 313-321.

Zama U, Moreira J, Báo SN, Campos LAO, Dolder H, Lino-Neto J, nigrophthalmus Melo M (2007). Morphology of testicular and post-testicular spermatozoa in Microstigmus arlei Richards, 1972 and M. nigrophthalmus Melo, 1992 (Hymenoptera: Apoidea: Pemphredoninae) with phylogenetic consideration. Arthropod Structure \& Development 36: 304-316. 